5. El-Husny A., Raiol-Moraes M., Amador M. và cộng sự. (2016). CDH1 mutations in gastric cancer patients from northern Brazil identified by Next- Generation Sequencing (NGS). Genet Mol Biol, 39(2), 189-198.

6. Choi J.-H., Kim Y.-B., Ahn J.M. và cộng sự. (2018). Identification of genomic aberrations associated with lymph node metastasis in diffusetype gastric cancer. Exp Mol Med, 50(4), 1-11.

7. Camargo M.C., Goto Y., Zabaleta J. và cộng sư. (2012). Sex hormones, hormonal interventions, and gastric cancer risk: a meta- analysis. Cancer Epidemiol Biomark Prev Publ Am Assoc Cancer Res Cosponsored Am Soc Prev Oncol, 21(1), 20-38.

8. Oliveira C., Sousa S., Pinheiro H. và cộng sự. (2009). Quantification of epigenetic and genetic 2nd hits in $\mathrm{CDH} 1$ during hereditary diffuse gastric cancer syndrome progression. Gastroenterology, 136(7), 2137-2148.

9. Chen Q.-H., Deng W., Li $X_{\text {. }}-W$. và cộng sự. (2013). Novel $C D H 1$ germline mutations identified in Chinese gastric cancer patients. World J Gastroenterol WJG, 19(6), 909-916.

\title{
NGHIÊN CỨU ĐĂC ĐIỂM TỔN THƯƠ'NG HẮC VÕNG MẠC QUANH ĐĨA THI TRÊN LÂM SÀNG VÀ CHIÊUU DÀY LỚP SỢI THẦN KINH QUANH ĐĨA THỊ TRÊN OCT Ở MẮT CÂ̂N THI CAO
}

\section{TÓM TẮT}

Mục tiêu: Đánh giá đặc điểm tổn thương hắc võng mạc quanh đĩa thị trên lâm sàng, chiều dày của lớp sợi thần kinh quanh đĩa thi bằng OCT trên mắt cận thị cao và một số yếu tố liên quan. Đối tượng và phương pháp nghiên cứu: Nghiên cứu mổ tả cắt ngang trên 168 mắt của 88 bệnh nhân có mức độ cận thị $\leq-6.00 D$, tại khoa Khúc xạ - Bệnh viện Mắt Trung Ương. Kết quả: số mắt có tổn thương hắc võng mạc quanh đĩa thi là 118 mắt $(70,2 \%)$. Chiêu dày trung bình lớp sợi thần kinh quanh đĩa thị là $88,21 \pm 8,74$ $\mu \mathrm{m}$, trong đó chiều dày lớp sợi thần kinh quanh đĩa thị ở những trưởng hợp có tổn thương hắc võng mạc quanh đĩa thi $(86,39 \pm 8,04 \mu \mathrm{m})$ mỏng hơn so với những trường hợp không có tổn thương hắc võng mạc quanh đĩa thi $(92,52 \pm 8,92 \mu \mathrm{m})$, sự khác biệt có ý nghĩa thống kê $(p<0,01)$. Khi thời gian mắc cận thị càng lâu, mức độ cận càng cao và chiều dài trục nhãn cầu càng dài thì càng có nguy cơ tổn thương hẳc võng mạc quanh đĩa thị. Khi mức độ cận càng cao thì lớp sợi thân kinh quanh đĩa thị càng mỏng. Kết luận: Trên mắt cận thị cao, ba yếu tố: thời gian mắc cận thị, mức đô cận thí, và chiều dài trục nhãn câu có liên quan với tổn thương hắc võng mạc quanh đĩa thị. Chiều dày lớp sợi thần kinh quanh địa thi ở mắt có tổn thương hắc võng mạc quanh đĩa thị mỏng hơn ở mắt không có tổn thương. Yếu tố mức độ cận thị có liên quan với chiều dày lớp sợi thần kinh quanh đĩa thị.

\section{SUMMARY}

STUDYING CHARACTERISTIC OF CHOROIDAL RETINAL DAMAGE AROUND THE OPTICAL DISC IN CLINIC AND THE

${ }^{1}$ BV Mắt trung ương

Chịu trách nhiệm chính: Nguyễn Thị Thu Hiền

Email: Thuhienvnio@gmail.com

Ngày nhận bài: 18.2.2021

Ngày phản biên khoa hoc: 26.3.2021

Ngày duyệt bài: 7.4.2021
Nguyễn Thị Thu Hiền'1, Phạm Thị Minh Châu ${ }^{1}$

\section{NERVE FIBER LAYER THICKNESS AROUND} THE OPTICAL DISC BY OCT IN HIGH MYOPIA

Objective: To assess the characteristic of choroidal retinal damage around the optical disc in clinic, the nerve fiber layer thickness around the optical disc by OCT in high and risk factors. Methods: A cross-sectional study on 168 eyes of 88 patients with high myopia was conducted between January 2020 and August 2020 at the Refraction Department of Vietnam National Institute of Ophthalmology. Results: the number of eyes with choroidal retinal damage around the optical disc was 118 eyes $(70.2 \%)$. The average thickness of the nerve fiber layer around the optical disc was $88.21 \pm 8.74 \mu \mathrm{m}$, in which the thickness of the nerve fiber layer around the optic disc in the eyes with choroidal retinal damage around the optical disc $(86.39 \pm 8.04 \mu \mathrm{m})$ was thinner than this of the eyes without the damage $(92.52 \pm 8.92 \mu \mathrm{m})$, the difference was statistically significant $(p<0.01)$. The longer of myopia duration, the higher of myopia level, and the longer of axis length, the risk of choroidal retinal damage around the optical disc was higher. The higher of myopia level, the thickness of the nerve fiber layer around the optic disc was thinner. Conclusions: In high myopic eyes, three factors: the duration of myopia, the degree of myopia, and the axis length were associated with choroidal retinal damage around the optical disc. The thickness of the nerve fiber layer around the optic disc in the eyes with choroidal retinal damage around the optical disc was thinner than this of the eyes without the damage. Myopic level factors are associated with the thickness of the nerve fiber layer around the optical disc.

\section{I. ĐẶT VẤN ĐỀ}

Cân thị, đặc biệt cận thị cao là tật khúc xa phổ biến hiện nay, gây ảnh hưởng chủ yếu đến thị lực nhìn xa, làm suy giảm chất lượng cuộc sống đồng thời gây ra gánh nặng kinh tế đáng 
kể cho cá nhân và toàn xã hội. Theo Tổ chức y tế thế giới năm 2010, tỷ lệ cận thị chiếm khoảng $28 \%$ dân số thế giới (1,9 tỷ người), trong đó cận thị cao chiếm 3\% (205 triệu người). Dự đoán đến năm 2050, tỷ lệ cận thị sẽ lên đến $52 \%$ dân số thế giới (khoảng 5 tỷ người), trong đó cận thị cao chiếm $10 \%$ (khoảng 911 triệu người) ${ }^{1}$.

Cân thị cao thường liên quan đến sự kéo dài quá mức của trục nhãn cầu, nhiều nghiên cứu trên thế giới chỉ ra rằng có mối liên quan giữa chiều dày lớp sợi thần kinh quanh gai và mức độ cận thị cũng như chiêu dài trục nhãn cầu. Nghiên cứu của Wang $(2018)^{3}$ chỉ ra rằng chiều dày lớp sợi thần kinh trên OCT có liên quan đến mức độ cận thị, khi mức độ cận càng cao thì lớp sợi thần kinh quanh gai càng mỏng. Với việc tích hợp các kỹ thuật mới như chụp cắt lớp võng mạc quang hoc OCT (optical coherence tomography) giúp hỗ trợ các bác sỹ nhãn khoa trong việc phát hiện, theo dõi lớp sợi thần kinh quanh gai trên các mắt cân thị cao².

Trên thế giới và tại Việt Nam, đã có một số nghiên cứu về đặc điểm tổn thương trên OCT đĩa thị trên các mắt bị glocom có cận thị $\mathrm{cao}^{3,4}$. Nhưng chỉ số chiều dày lớp sợi thần kinh quanh đĩa thị (RNFL) trên các mắt cận thị cao có hoặc không có tổn thương đĩa thị phối hợp chưa được nghiên cứu đầy đủ. Vì vậy chúng tôi thực hiển đề tài này nhằm mục tiểu: Đánh giá đắc điểm tổn thương võng mạc quang đĩa thị trên lâm sàng, chiều dày của lớp sợi thần kinh quanh đĩa thi bằng OCT trên mắt cận thị cao và một số yêu tố liên quan.

\section{II. ĐỐI TƯợNG VÀ PHƯƠNG PHÁP NGHIÊN CỨU}

1. Đối tượng nghiên cứu. Bệnh nhân từ 12 tuổi trở lên, được chẩn đoán cận thị từ -6.00D trở lên sau soi bóng đồng tử có tra thuốc liệt điều tiết, ở một hoặc hai mắt, có hoặc không kèm loạn thị, khám tại khoa Khúc xạ - Bệnh viện mắt Trung ương từ tháng 01/2020 đến tháng 08/2020.

Loại trừ: bệnh nhân có các bệnh lý toàn thân có biểu hiện tại mắt, tiền sử chẩn thương, phẫu thuật nội nhãn, tiền sử bệnh võng mạc trẻ đẻ non. Bệnh nhân có bệnh lý tại mắt: đục môi trường trong suốt, bệnh lý võng mạc khồng do cận thị, glocom, bệnh lý thị thần kinh.

\section{Phương pháp nghiên cứu}

Thiết kế nghiên cứu: mô tả cắt ngang

Cỡ mẫu nghiên cứu: 168 mắt của 88 bệnh nhân Qui trình nghiên cứu:

- Hỏi bệnh: xác định thời điểm mắc cận thị, tiền sử gia đình, cũng như loại trừ các bệnh lý tại mắt và toàn thân không phù hợp với nghiên cứu.

- Soi bóng đồng tử sau nhỏ thuốc liệt điêu tiết Cyclogyl $1 \%$ để xác định tình trạng khúc xạ

- Khám nhãn cầu bằng sinh hiển vi khám bệnh để đánh giá tình trạng bán phần trước và tình trạng dịch kính, đĩa thị, võng mạc trung tâm, võ̃ng mạc chu biên. Chia tổn thương hắc võng mạc quanh đĩa thị thành 4 góc phần tư (phía trên, phía mũi, phía dưới và phía thái dương)

- Siêu âm nhãn cầu: đánh giá tình trạng dịch kính, võng mạc và chiều dài trục nhãn cầu.

- Chụp OCT với đồng tử giãin tối đa: Phần đĩa thị lấy các chỉ số chiều dày lớp sợi thần kinh quanh đĩa thi

Xử lí số liệu: số liệu được thu thập và xử lí bằng phần mềm SPSS 22.

\section{KẾT QUẢ NGHIÊN CỨU VÀ BÀN LUÂ̂N}

3.1 Đặc điểm tổn thương hắc võng mạc quang đĩa thị trên lâm sàng, chiêu dày của lớp sợi thân kinh quanh đĩa thị bằng $\mathrm{OCT}$ trên mắt cận thị cao. Cận thị cao do sự kéo dài trục nhãn cầu và liên quan đến sự thay đổi cấu trúc của protein collagen, có thể dẫn đến những thay đổi thoái hóa và mỏng của võng mạc, hắc mạc và củng mạc.

Tổn thương teo võng mạc quanh đĩa thị đĩa là loại tổn thương phổ biến trền bệnh nhân cận thị, nhất là cận thị cao. Nguyên nhẩn chủ yếu là do khi trục nhãn cầu kéo dài hơn bình thường có sự xoay theo trục đứng của củng mạc về phía mũi, đồng thời do sự dịch chuyển không tương xứng với hắc mạc và võng mạc, để lộ vùng thoái hoá tổ chức.

Bảng 3.1. Tỷ lệ tổn thương hắc vông mạc quanh đĩa thị trên lâm sàng và chỉ số chiều dày lớp sợi thần kinh quanh đĩa thị trên OCT tương ứng

\begin{tabular}{|c|c|c|c|}
\hline \multicolumn{2}{|l|}{ Tốn } & $\begin{array}{c}\text { Số lượng } \\
\text { (mắt), tỷ lệ } \\
(\%)\end{array}$ & $\begin{array}{l}\text { Chiều dày } \\
\text { RNFL trên } \\
\text { OCT ( } \mu \mathrm{m})\end{array}$ \\
\hline \multicolumn{2}{|c|}{ Không tổn thương } & $50(29,8 \%)$ & $92,52 \pm 8,92$ \\
\hline \multirow{5}{*}{$\begin{array}{c}\text { Tổn } \\
\text { thương } \\
\text { hắc } \\
\text { võng } \\
\text { mạc } \\
\text { quanh } \\
\text { đĩa thị }\end{array}$} & $\leq 1 / 4$ & $65(38,7 \%)$ & \\
\hline & $\begin{array}{c}>1 / 4 \text { đến } \\
\leq 2 / 4\end{array}$ & $35(20,8 \%)$ & \\
\hline & $\begin{array}{c}>2 / 4 \text { đến } \\
\leq 3 / 4\end{array}$ & $8(4,8 \%)$ & \\
\hline & $\begin{array}{c}>3 / 4 \text { đến } \\
\leq 4 / 4\end{array}$ & $10(6 \%)$ & \\
\hline & Chung & $118(70,2 \%)$ & $86,39 \pm 8,04$ \\
\hline \multicolumn{2}{|c|}{ Tổng } & $168(100 \%)$ & $88,21 \pm 8,75$ \\
\hline
\end{tabular}

Theo bảng 3.1, tổng số mắt không có tổn thương hắc võng mac quanh đĩa thi là 50 mắt $(29,8 \%)$ ít hơn số mắt có tổn thương là 118 mắt 
$(70,2 \%)$, sự khác biệt này có ý nghĩa thống kê với $p<0,01$. Trong nhóm có tổn thường, chủ yếu chỉ tổn thương góc $1 / 4$ là 65 mắt $(38,7 \%)$, tiếp theo các mức $2 / 4,3 / 4$ và $4 / 4$ với tỷ lệ lần lượt là 35 mắt $(20,8 \%), 8$ mắt $(4,8 \%)$ và 10 mắt $(6 \%)$. Nghiên cứu của Jonsson $(2005)^{5}$ trên quần thể người ngẫu nhiên từ 50 tuổi trở lên với 1012 mắt được đánh giá thì chỉ thấy có $22,0 \%$ có tổn thương teo hắc võng mạc quanh đĩa thị. Nghiên cứu của chúng tôi trên đối tượng cận thị cao nên có trục nhãn cầu dài hơn bình thương, do đó dẫn đến teo hắc võng mạc quanh đĩa thị. Kết quả của chúng tôi thấp hơn so với Koh $(2013)^{6}$ đưa ra: tỷ lệ teo hắc võng mạc quanh đĩa thị là $81 \%$ và cao hơn trong nghiên cứu của Đ.H.Giang $(2017)^{7}$ đưa ra: tỷ lệ teo hắc võng mạc quanh đĩa thị là 60,3\%.

Chiều dày trung bình lớp sợi thần kinh quanh đĩa thị là $88,21 \pm 8,74 \mu \mathrm{m}$, trong đó lớp sợi thần kinh quanh đĩa thị mỏng nhất là $65 \mu \mathrm{m}$, dày nhất là $117 \mu \mathrm{m}$. Số mắt có teo mỏng lớp sợi thần kinh quanh đĩa thị là 61 mắt $(36,3 \%)$, ít hơn số mắt không có teo mỏng lớp sợi thần kinh quanh đĩa thị là 107 mắt $(63,7 \%)$. Điều này có thể giải thích là do đa số bệnh nhân trong nhóm nghiên cứu ở lứa tuổi trẻ, thời gian mắc cận thị chưa dài nên có thể chưa gây ra những tổn thương teo mỏng lớp sợi thần kinh quanh đĩa thị. Kết quả độ dày trung bình lớp sợi thần kinh quanh đĩa thị trong nghiên cứu của chúng tôi cũng tương tự với kết quả của Koh và cộng sự (2016) ${ }^{6}$ nghiên cứu trên bệnh nhân cận thị cao đưa ra kết quả độ dày lớp sợi thần kinh quanh đĩa thị là 92,48 \pm $9,99 \mu \mathrm{m}$. Tuy nhiên chiêu dày lớp sợi thần kinh quanh đĩa thị ở những trưởng hợp có tổn thương hắc võng mạc quanh đĩa thị $(86,39 \pm 8,04 \mu \mathrm{m})$ mỏng hơn so với những trưởng hợp không có tổn thương hắc võng mạc quanh đĩa thị $(92,52 \pm$ $8,92 \mu \mathrm{m})$, sự khác biệt có ý nghĩa thống kê $(p<0,01)$.

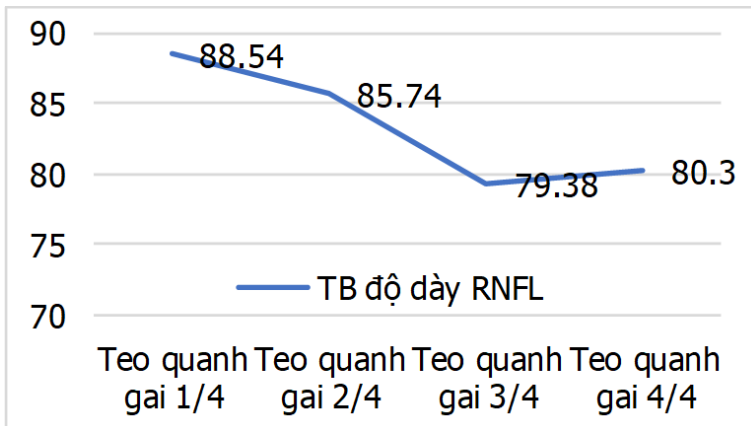

Biêu đồ 3.1. Độ dày RNFL quanh đĩa thị tương ứng với tổn thương trên lâm sàng

Theo biểu đồ 3.1 , chiều dày lớp sợi thần kinh quanh đĩa thị giảm dần tương ứng với mức độ tổn thương hắc võng mạc quanh đĩa thị trên lâm sàng, sự khác biệt này có ý nghĩa thống kê với $p<0,01$.

3.2 Đánh giá một số yếu tố liên quan đến tổn thương hắc võng mạc quanh đĩa thị trên lâm sàng và chiêu dày của lớp sợi thân kinh quanh đĩa thị trên OCT.

Bảng 3.2 Liên quan giữa các mức độ tổn thương hắc vông mạc quanh đĩa thị và một số yếu tố

\begin{tabular}{|c|c|c|c|c|c|c|c|}
\hline \multirow{2}{*}{$\begin{array}{l}\text { Yếu tố } \\
\text { liên quan }\end{array}$} & \multirow[t]{2}{*}{ Tốn thương } & \multirow{2}{*}{$\begin{array}{c}\text { Không } \\
\text { tổn } \\
\text { thương } \\
\end{array}$} & \multicolumn{4}{|c|}{ Có tốn thương } & \multirow[b]{2}{*}{ Tổng } \\
\hline & & & $\leq 1 / 4$ & $\begin{array}{c}\text { Từ }>1 / 4 \\
\leq 2 / 4 \\
\end{array}$ & $\begin{array}{c}\text { Từ >2/4- } \leq \\
3 / 4\end{array}$ & $\begin{array}{c}\text { Từ }>3 / 4 \\
\leq 4 / 4\end{array}$ & \\
\hline \multirow{3}{*}{$\begin{array}{l}\text { Mức độ } \\
\text { cận thị }\end{array}$} & $\begin{array}{c}\text { Từ -6,00D đến - } \\
\text { 8,75D }\end{array}$ & 42 & 41 & 18 & 3 & 0 & 104 \\
\hline & $\begin{array}{c}\text { Từ -9,00D đến - } \\
11.75 \mathrm{D}\end{array}$ & 8 & 24 & 12 & 4 & 0 & 48 \\
\hline & Trên $-12,00 \mathrm{D}$ & 0 & 0 & 5 & 1 & 10 & 16 \\
\hline \multirow{4}{*}{$\begin{array}{l}\text { Thời gian } \\
\text { mắc cận thị }\end{array}$} & Từ 1- 5 năm & 14 & 6 & 1 & 0 & 0 & 21 \\
\hline & từ 6 - 10 năm & 17 & 31 & 18 & 2 & 0 & 68 \\
\hline & từ 11 - 15 năm & 15 & 17 & 18 & 3 & 3 & 56 \\
\hline & trên 16 năm & 4 & 3 & 6 & 3 & 7 & 23 \\
\hline \multirow{4}{*}{ Độ tuổi } & Từ $12-<20$ tuối & 32 & 49 & 21 & 5 & 3 & 110 \\
\hline & Từ $20-<30$ tuối & 16 & 11 & 8 & 0 & 2 & 37 \\
\hline & Từ 30-<40 tuối & 2 & 5 & 6 & 1 & 2 & 16 \\
\hline & $>40$ tuối & 0 & 0 & 0 & 2 & 3 & 5 \\
\hline \multirow{3}{*}{$\begin{array}{l}\text { Chiều dài } \\
\text { trục nhãn } \\
\text { câu }\end{array}$} & Từ $24-<26 \mathrm{~mm}$ & 10 & 10 & 1 & 0 & 0 & 21 \\
\hline & Từ $26-<28 \mathrm{~mm}$ & 36 & 41 & 15 & 7 & 0 & 99 \\
\hline & $>28 \mathrm{~mm}$ & 4 & 14 & 19 & 1 & 10 & 48 \\
\hline
\end{tabular}


Nghiên cứu của chúng tôi đã chỉ ra rằng giá trị trung bình của 3 yếu tố: thời gian mắc cận thị, mức độ cận thị, và chiều dài trục nhãn cầu giữa nhóm có teo hắc võng mạc quanh đĩa thị và không có tổn thương có sự khác biêt có ý nghĩa thống kê. Đồng thời bằng cách tính tỉ suất chênh OR cũng khẳng định 3 yếu tố trên có liên quan đến nguy cơ tổn thương đĩa thị và vùng hắc võng mạc quanh đĩa thị. Khi thời gian mắc cận thị càng lâu, mức độ cận càng cao và chiều dài trục nhãn cầu càng dài thì càng có nguy cơ tổn thương hắc võng mạc quanh đĩa thị. Điều này có thể giải thích là độ tuổi phát hiên cận thi trong nghiên cứu trung bình là $9,13 \pm 3,57$; đa số phát hiện ở lứa tuổi tiểu học nên cùng với sự phát triển của nhãn cầu, mức độ cận thị và chiều dài

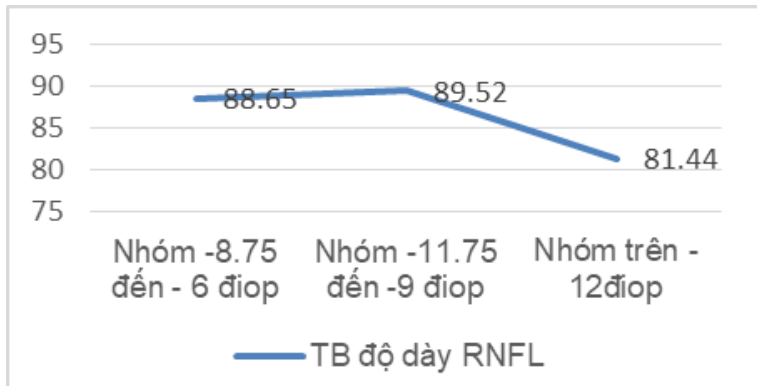

Biểu đồ 3.2. Chiều dày RNFL trên OCT và múc độ cận thị

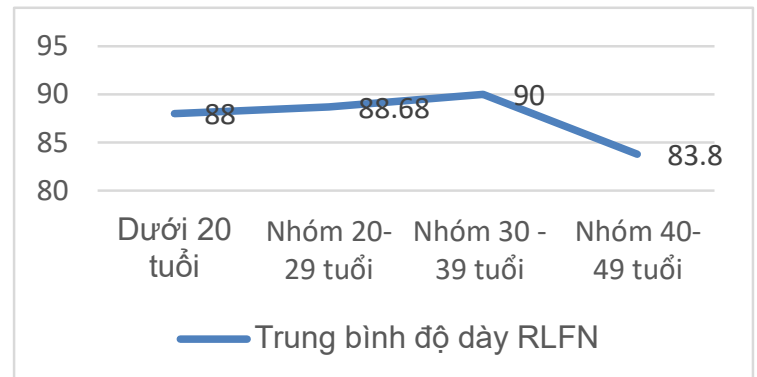

\section{Biểu đồ 3.4. Chiều dày RNFL trên OCT và độ tuổi}

Đã có nhiều nghiên cứu trên thế giới chỉ ra rằng có mối liên quan giữa chiều dày lớp sợi thần kinh quanh đĩa thị và mức độ cận thị cũng như chiều dài trục nhãn cầu, nhưng không thây có mối liên quan đến một số yếu tố khác như tuổi, tuổi phát hiện cận ${ }^{8}, \ldots$ Trong nghiên cứu của chúng tôi cũng thấy rằng mức độ cận thị có liên quan đến tổn thương teo lớp sợi thần kinh quanh đĩa thị trên OCT. Điều này có thể giải thích khi mức độ cận càng cao thì những những biến đổi ở đáy mắt càng nhiều, làm lớp sợi thần kinh quanh đĩa thị cũng mỏng hơn. Kết quả này trục nhãn cầu ngày càng tăng lên theo thời gian. Nguyên nhân gây tổn thương hắc võng mạc quanh đĩa thị chủ yếu là do sự xoay trục không tương xứng giữa củng mạc và hắc võng mạc khi trục nhãn cầu kéo dài ra. Do vậy khi thời gian cận thị càng lâu, mức độ cận thị càng cao và chiều dài trục nhãn cầu càng dài thì càng có nguy cơ gây tổn thương đĩa thị và vùng hắc võng mạc quanh đĩa thị. Kết quả này cũng tương tự với một số nghiên cứu trên thế giới như Koh và cộng sự (2013) nghiên cứu trên 120 bệnh nhân cận thị cao để tìm mối liên quan giữa các yếu tố nguy cơ và tổn thương đĩa thị thấy rằng: khi chiều dài trục nhãn cầu lớn hơn $26,5 \mathrm{~mm}$ thì nguy cơ tổn thương đĩa thị tăng lên.

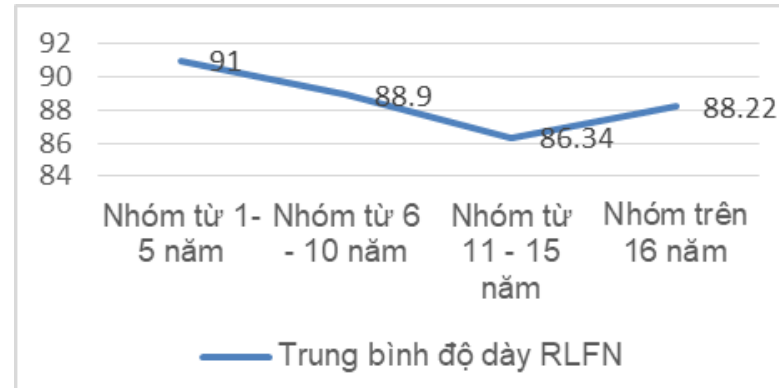

Biểu đồ 3.3. Chiều dày RNFL trên OCT và thời gian mắc cận thị

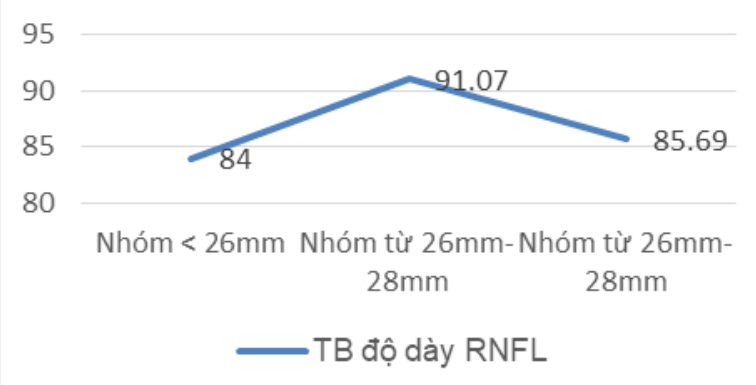

\section{Biểu đồ 3.5. Chiều dày RNFL trên OCT và chiều dài trục nhãn cầu}

tương tự với nghiên cứu của Wang $(2018)^{3}$ chỉ ra rằng chiều dày lớp sợi thần kinh trên OCT có liên quan đến mức độ cận thị, khi mức độ cận càng cao thì lớp sợi thần kinh quanh đĩa càng mỏng.

Ngoài ra nghiên cứu của chúng tôi cũng chỉ ra các yếu tố liên quan khác như tuổi, tuổi phát hiện cận thị, tiền sử gia đình, chiều dài trục nhãn cầu không có liên quan đến tổn thương teo lớp sợi thần kinh quanh đĩa thị trên OCT.

\section{KẾT LUÂN}

Trên mắt cận thị cao, tỷ lệ tổn thương hắc võng mạc quanh gai là $70,2 \%$. Ba yếu tố: thời 
gian mắc cận thị, mức độ cận thị, và chiêuu dài trục nhãn cầu có liên quan với tổn thương hắc võng mạc quanh đĩa thị.

Chiều dày lớp sợi thân kinh quanh đĩa thị ở mắt có tổn thương hắc võng mạc quanh đĩa thị mỏng hơn ở mắt không có tổn thương. Yếu tố mức độ cận thị có liên quan với chiều dày lớp sợi thần kinh quanh đĩa thị.

\section{TÀI LIÊU THAM KHẢO}

1. Holden BA, Fricke TR, Wilson DA, et al. Global Prevalence of Myopia and High Myopia and Temporal Trends from 2000 through 2050. Ophthalmology. 2016;123(5):1036-1042.

2. Ng DS, Cheung CYL, Luk FO, Lai TYY et al. Advances of optical coherence tomography in myopia and pathologic myopia, Eye (Lond). (2016) Jul;30(7):901-16

3. Wang C-Y, Zheng Y-F, Liu B, et al. Retinal Nerve Fiber Layer Thickness in Children: The Gobi
Desert Children Eye Study. Invest Ophthalmol Vis Sci. 2018;59(12):5285-5291.

4. Nguyễn Thanh Thủy. Nghiên cứu đăc điểm lâm sàng và cận lâm sàng của mắt cận thị cao tại bệnh viện mắt trung ương. Luận văn Thạc sĩ y học. Đại học Y Hà Nội; 2012.

5. Jonsson $\dot{O}$, Damji KF, Jonasson $F$, et al. Epidemiology of the optic nerve grey crescent in the Reykjavik Eye Study. $\mathrm{Br}$ J Ophthalmol. 2005;89(1):36-39.

6. Koh VT, Nah GK, Chang $L$, et al. Pathologic changes in highly myopic eyes of young males in Singapore. Ann Acad Med Singapore. 2013;42(5):216-224.

7. Đoàn Hương Giang. Đăc điểm lâm sàng cân thị cao ở trẻ em và kết quả chỉnh kính. Luận văn Thạc sĩ y học. Đai học Y Hà Nội; 2017

8. Chen $S$, Wang $B$, Dong $N$, Ren $X$, Zhang $T$, Xiao L. Macular measurements using spectraldomain optical coherence tomography in Chinese myopic children. Invest Ophthalmol Vis Sci. 2014;55(11):7410-7416.

\section{CHI PHÍ TRỰC TIẾP ĐIỀU TRI UNG THƯ ĐẠI TRỰC TRÀNG TẠI VIÊ̂T NAM, NĂM 2019}

\section{TÓM TẮT}

Mục tiêu: Nghiên cứu được thực hiện nhằm đo lường chi phí trực tiếp điều trị ung thư đại trực tràng tại Việt Nam năm 2019.Phương pháp nghiển cứu: Nighiên cứu mô tả cắt ngang, dựa trên hồi cứu số liêu từ hồ sơ thanh toán khi ra viện và phỏng vấn 89 người bênh ung thư đại trực tràng hoàn thành đợt điêu trị trong thời gian thu thập số liệu của nghiển cứu, từ tháng 12/2019 đến tháng 6/2020 tai bênh viện K Trung ương. Kết quả và kết luận: Trong đợt điều trị hiện tại, tổng chi phí trực tiếp vào khoảng 43.484.000 VNĐ với chi phí thấp nhất là 11.988.000 VNĐ và chi phí cao nhất là 138.378.000 VNĐ. Đối với tổng chi phí trong năm 2019, tổng chi phí trực tiếp trung bình lên đến 246.813.000 VNĐ với chi phí thấp nhất là 11.988.000 VNĐ và chi phí cao nhất là 1.881.409.000 VNĐ. Trong các nhóm chi phí, chi phí tiền túi hộ gia đình đều chiếm tỷ trọng lớn hơn.

Tư khoá: Chi phí điều trị trực tiếp, ung thư đại trực tràng, Việt Nam

\section{SUMMARY \\ DIRECT COST OF COLORECTAL CANCER TREATMENT IN VIETNAM, 2019 \\ Objective: To measure the direct cost of}

\footnotetext{
*Trường Đại học Y tế Công Cộng

Chịu trách nhiệm chính: Nguyễn Quỳnh Anh

Email: nqa@huph.edu.vn

Ngày nhận bài: 19.2.2021

Ngày phản biên khoa học: 25.3.2021

Ngày duyệt bài: 6.4 .2021
}

\section{Nguyễn Quỳnh Anh*, Nguyễn Thu Hà*}

colorectal cancer treatment in Vietnam in 2019. Methods: Cross-sectional descriptive study, based on retrospective billing data from hospital discharge records and interviews with 89 colorectal cancer patients who completed treatment during data collection of the study, from December 2019 to June 2020 at Vietnam National Cancer Hospital. Results and conclusions: During the current treatment, the total direct cost was about 43,484,000 VND with the lowest cost of $11,988,000 \mathrm{VND}$ and the highest cost of $138,378,000$ VND. For total costs in 2019, the average total direct costs amount to VND 246,813,000 with the lowest cost of VND $11,988,000$ and the highest cost of VND 1,881,409,000. Among the cost groups, household out-of-pocket expenses accounted for a larger share.

Keywords; Direct treatment costs, colorectal cancer, Vietnam

\section{I. Đă̆T VẤN ĐỀ}

Mặc dù Việt Nam thuộc nhóm các quốc gia có thu nhập trung bình thấp, mô hình bệnh tật của Việt Nam lại có xu hướng tương tự như các quốc gia có thu nhập cao và thu nhập trung bình cao. Cụ thể, gánh nặng bệnh tật gầy ra bởi các bệnh không truyền nhiểm mà đặc biệt là các bệnh tim mạch và ung thư chiếm một tỷ trọng tăng dần trong cơ cấu bệnh tật. Gánh nặng bệnh tật của ung thư, đo lường thông qua giá trị số năm sống điều chỉnh theo mức độ tàn tật (Disability Adjusted Life Year, DALY), có xu hướng gia tăng trong giai đoạn 2008 - 2017. Cụ thể tổng DALY 